\title{
A social representations analysis of design science research
}

\author{
Rennie Naidoo*, Alta van der Merwe*, Aurona Gerber*†, Alan Hevner ${ }^{\ddagger}$ \\ * Department of Informatics, University of Pretoria, South Africa \\ $\dagger$ CAIR, CSIR Meraka, South Africa \\ $\ddagger$ Information Systems and Decision Sciences, University of South Florida, USA
}

\begin{abstract}
Compared to positivist survey and interpretive case study research, design science research (DSR) is a relatively novel and unfamiliar research paradigm within the computing field in South Africa. In light of recent interest in the DSR paradigm, this study sought to investigate how local computing researchers familiarise themselves with an unfamiliar paradigm and what their perspectives of DSR are. Key theoretical concepts from social representations theory (SRT), such as 'anchoring' and 'objectification', were used to explore how researchers constructed their understanding of DSR. A visual approach was used to administer drawing and association tasks to two focus groups; each focus group comprised around 25 participants ranging from doctoral students to experienced researchers. The focus group discussions invoked interesting complementary and distinctive associations about the process and content of DSR, specifically when anchored in dominant and conventional research practices. The results also illustrated several ways in which DSR is objectified in drawings and metaphorical constructions. This study concludes that SRT is useful for exploring beliefs about novel and relatively unfamiliar research practices. This study also contributes to an enhanced understanding of how computing researchers adapt to changing research practices. The findings are developed into recommendations for introducing changes to research practices. These recommendations can be used to direct efforts to more appropriately accommodate changing research practices within the computing community to broaden knowledge generation.
\end{abstract}

KEYWORDS: Design science research, anchoring, objectification, social representations theory, visual methods

CATEGORIES: K.0 [General]

\section{ARTICLE HISTORY}

Received 31 August 2014

Accepted 4 May 2015

\section{INTRODUCTION}

Scientific knowledge itself [is] a social product.

$$
\text { [1. p. 1] }
$$

Understanding the social and cognitive processes experienced by members of the computing research community in order to familiarise themselves with a new or unfamiliar research paradigm or approach is a promising area of research. Recently, computing scholars in the South African research community have shown a growing interest in exploring the potential of the design science research (DSR) paradigm [2. DSR is an appropriate paradigm to investigate because it has wide applicability within computing and has not had enough time to develop into an immutable research tradition - such as positivism. The issue of how computing researchers use social and cognitive processes

Email: Rennie Naidoo rennie.naidoo@up.ac.za, Alta van der Merwe alta.vdm@up.ac.za to assimilate new ideas and practices in a new research paradigm, such as DSR, remains underexplored.

Researchers, as advocates of theories, research paradigms and methods, are involved in the professional activity of creating and transmitting diverse representations through intersubjective processes [3, 4, 5. In this study, social representations theory (SRT) is posited as an analytical framework to understand how researchers make the unfamiliar familiar [6]. Computing research has relied on SRT in the past to examine important socio-cognitive aspects of the implementation and use of information systems (IS) [7, 8, 9, 10. However, the current use of SRT is almost silent on the diffusion and popularisation of new and unfamiliar concepts that directly concern the research community. Consequently, an incomplete picture exists about the way in which knowledge about new or unfamiliar research paradigms or approaches enter and become routinised into the everyday discourse and common sense of computing researchers.

Research groups or communities usually develop a 
shared world view, a collective memory and a common view of their history and future. Very often, these groups ignore how events and knowledge obtained in their past influence the meaning they attach to more contemporary research approaches, and therefore how they apply the new research approaches [11, 12. Thus, it is important to explore the collective and shared meaning of concepts within such groups to understand how researchers go about understanding new paradigms such as DSR. The research literature thus far acknowledged that computing scholars, and in particular, IS researchers, have a long tradition of drawing research approaches, methods and paradigms from other disciplines, including social sciences, economics and managerial sciences [13, 14. This diversity of research paradigms and approaches is often cited as an advantage, but some literature warns that there are disadvantages as well, and that researchers should take care to justify research theories [14, 15, 16.

This research study is concerned with the question of how (computing) researchers go about representing a relatively unfamiliar research paradigm. The questions, more specifically, in relation to DSR are as follows:

- What are the interesting complementary and distinctive associations that researchers make about the process and content of DSR when compared to familiar research paradigms?

- How do researchers anchor and objectify their understanding of DSR concepts by relying on more familiar concepts and images?

To answer these questions, response-limited studies, such as surveys where participants would have to concur with one of a pre-set range of views, would have been inappropriate. A visually led focus group discussion was therefore adopted so that participants could offer a wide range of responses in a more 'naturally occurring' context.

Literature has not yet examined, at the microsocial level, how researchers go about representing a relatively unfamiliar research paradigm. By drawing on insights provided by research in social psychology, this paper aims to contribute to enhancing our understanding of how researchers go about representing a relatively unfamiliar research paradigm. This study also aims to further our understanding of the use of visually led qualitative research approaches within computing research. Based on the findings, the study aims to formulate recommendations that should be taken into consideration when adopting a new paradigm.

The rest of the paper is organised as follows: Section 2 locates DSR within the broader computing discipline and research traditions. Section 3 introduces the notion of social representation to understand how individuals and groups cope with unfamiliar social objects. Section 4 (the methodology section) presents the research design of the qualitative fieldwork that combined two focus group discussions and a visual design method to understand the dynamics of the various computing researchers' representations. Section 5 (the analysis) details the interesting complementary and distinctive associations researchers made about the process and content of DSR, and how these were often anchored in the participants' understanding of more familiar research paradigms. The analysis also illustrates ways in which DSR is objectified by the researchers in drawings and metaphorical constructions. Section 5 presents the results and discusses the implications and recommendations of these findings for computing research. Finally, Section 6 (the conclusion) presents the limitations of the research, summarises its main contributions and suggests avenues for future research.

\section{A HISTORICAL OVERVIEW OF COMPUT- ING RESEARCH TRADITIONS AND DSR}

A social representation analysis of new research practices relies on a historical and macro-social perspective to better contextualise current research traditions and perspectives. This section explores the history of research paradigms within computing, the umbrella discipline that includes informatics, IS and computer science. Informatics or IS is a relatively young field, almost three decades younger than the often-associated domain of computer science. The first academic diploma offered in computer science was the Diploma in Computer Science (introduced as a conversion course in 1953 by the University of Cambridge in England [17). The early publications in IS appeared almost 30 years later in the late 1970s (e.g. Management Information Systems Quarterly (MISQ) in 1977) and early 1980s. Many of these early publications in IS or Management Information Systems (MIS) focused on the nature of IS and the challenges faced within the domain [18. The need for the training of postgraduate students in relevant IS research paradigms and approaches, especially in the construction of theories, scientific inquiry, etc., was also one of the issues raised by Dickson, Benbasat and King [18. They argued that students need to be exposed to various data collection methodologies relevant to IS, such as survey research, field studies, experimentation in the laboratory and the field, simulation studies and protocol analysis.

A publication that influenced much of the research done in IS during the 1980s was a book written by Burrel and Morgan 19, which introduced their model of organisational analysis. This model classifies sociological theories along the two orthogonal dimensions of regulation vs. change and subjectivity vs. objectivity [19]. Klein 20] and Hirschheim and Klein 21] discussed how Burrel and Morgan's perspectives can be used to the advantage of the IS domain and, subsequently, Burrel and Morgan [19] were often referenced in IS publications in the 1980s and 1990s. For example, Deetz 22] discussed different management situations directly benefiting from the work of Burrel and Morgan. Naturally, some authors were of the opinion that Burrel and Morgan's view was simplistic and argued for a pluralist approach to IS research [15. This notion permeated opinions in IS research and recent publications (Venkatesh and Brown [23, for instance) argued for the use of mixed methods research where quantitative and qualitative methods are combined in the same 
research inquiry.

Orlikowski and Baroudi 24 reflected on the evolution of IS from 1983 to 1988 by examining 155 IS research papers. They found that $96.8 \%$ of all papers published reside in the positivist realm and suggested the use of interpretive and critical research as methodological alternatives. Walsham 25 investigated aspects of the history and state of interpretivism in IS research and provided some conceptual ideas and a reference point for further work in this relatively neglected area of research. Ngwenyama and Lee [26] provided a new perspective on the subject with a study on the communication richness in computerised mediated communication using critical social theory in 1997. They also argued for the use of critical theory as a method.

In 2004, Chen and Hirschheim 27] reflected on the evolution of the IS field over three decades, and more specifically on the paradigmatic and methodological progress made since 1991. They examined 1,893 papers published in eight major IS publication outlets and found that positivist research still dominates $81 \%$ of published empirical research. In particular, US journals, as opposed to European journals, tend to be more positivist, quantitative, cross-sectional and survey-oriented [27].

The use of design as a research method emerged in the early 1960s as a preferred approach in engineering. In 1967, Nadler 28] reasoned that for design and engineering projects, a more pragmatic research approach is needed than using methodologies borrowed from other disciplines. Nadler also argued that the scientific methodology, with analysis as the focus, restricted the effectiveness of a design solution and that a design strategy with function determination and ideal systems development as hallmarks enabled better results than the use of conventional strategies 28 . Kuhn 12 also referred to the existence of significant problem anomalies and indicated that these problems cannot be resolved using the traditional methods of scientism.

Simon 29 published his 'The sciences of the artificial' in 1969. The argument made by Simon, and often quoted by other authors, is that entities are categorised as being artificial since they depend on the "goals" of the person involved in the design of the artefact [29]. The result is that the goal defines the design. This is in contrast with natural phenomena, which evolve based on natural laws.

Klein 20] called on IS researchers to acknowledge the importance of "relevant" research and, by the turn of the century, there were many more arguments for IS research to be more relevant [30, 31, 32. In an effort to make IS research more relevant, certain researchers introduced system analysis and design as used for application development as an approach for research [21, 33, 34. There were even authors who indicated that there is potential in the use of an IS design approach. These authors included Walls, Widmeyer and El Sawy 35. and Carroll and Swatman 36. However, DSR, as an approach, only received wide attention after two events in 2004: the publication of Hevner, March, Park and Ram's paper on design science in IS [37, and the introduction of DSR on the website of the Association of Information Systems, hosted by Design Science Research in Information Systems and Technologies (DESRIST) 38. Fig. 1 provides a timeline with regard to some publications related to DSR.

The number of publications on DSR rose with contributions from different authors on the value of DSR. Gregor and Jones 39] identified eight separate components of design theories. Hevner [40] extended the 2004 paper 37] with a publication on a threecycle view for DSR. Peffers, Tuunamen, Rothenberger and Chatterjee 41] also provided a DSR methodology for IS research, while Pries-Heje and Baskerville [42] used concepts from design research to develop a design theory nexus.

A new debate started on the differences between action research and design research, and Iivari and Venable 43. presented a valuable comparison between these two approaches when they analysed the two approaches from several perspectives, including paradigmatic assumptions of ontology, epistemology, methodology and ethics. They identify that

action research often does not share the paradigmatic assumptions and the research interests of DSR, that some activities in DSR are always mutually exclusive from action research, and that there may be no, little or significant (but not total) overlaps between action research and DSR 43.

In Europe, a discussion started on the value and scientific quality associated with artefacts resulting from design and more pragmatic approaches. Junglas, Spiekermann, Stahl, Weitzel and Baskerville 44] published the memorandum that has engendered much debate in the German-speaking IS community, the Memorandum on Design-oriented IS Research. For the German IS community, the memorandum intends to:

- demonstrate that design science is a leading IS research paradigm in the German-speaking countries and thus justifies design science departments in journals, tracks in conferences, and themes in their selection and promotion processes;

- provide a foundation for future consolidated guidelines with regard to design science stakeholders, objects, goals, results, processes, methods and principles; and

- establish the DSR goal of 'rigour of artefact construction' as a valuable addition to its grounding in relevance.

These forms of rigour and relevance do not necessarily replace other expectations for grounding, but in some cases may become additional expectations 44.

Baskerville, Lyytinen, Sambamurthy and Straub 45] reacted to the memorandum, and more specifically to the bias towards an 'Anglo-Saxon' behavioural paradigm in North America and the behavioural paradigm in top IS journals. They claim that "a large portion of successful IS research in the Anglo-Saxon world does, indeed, follow the design-oriented research 


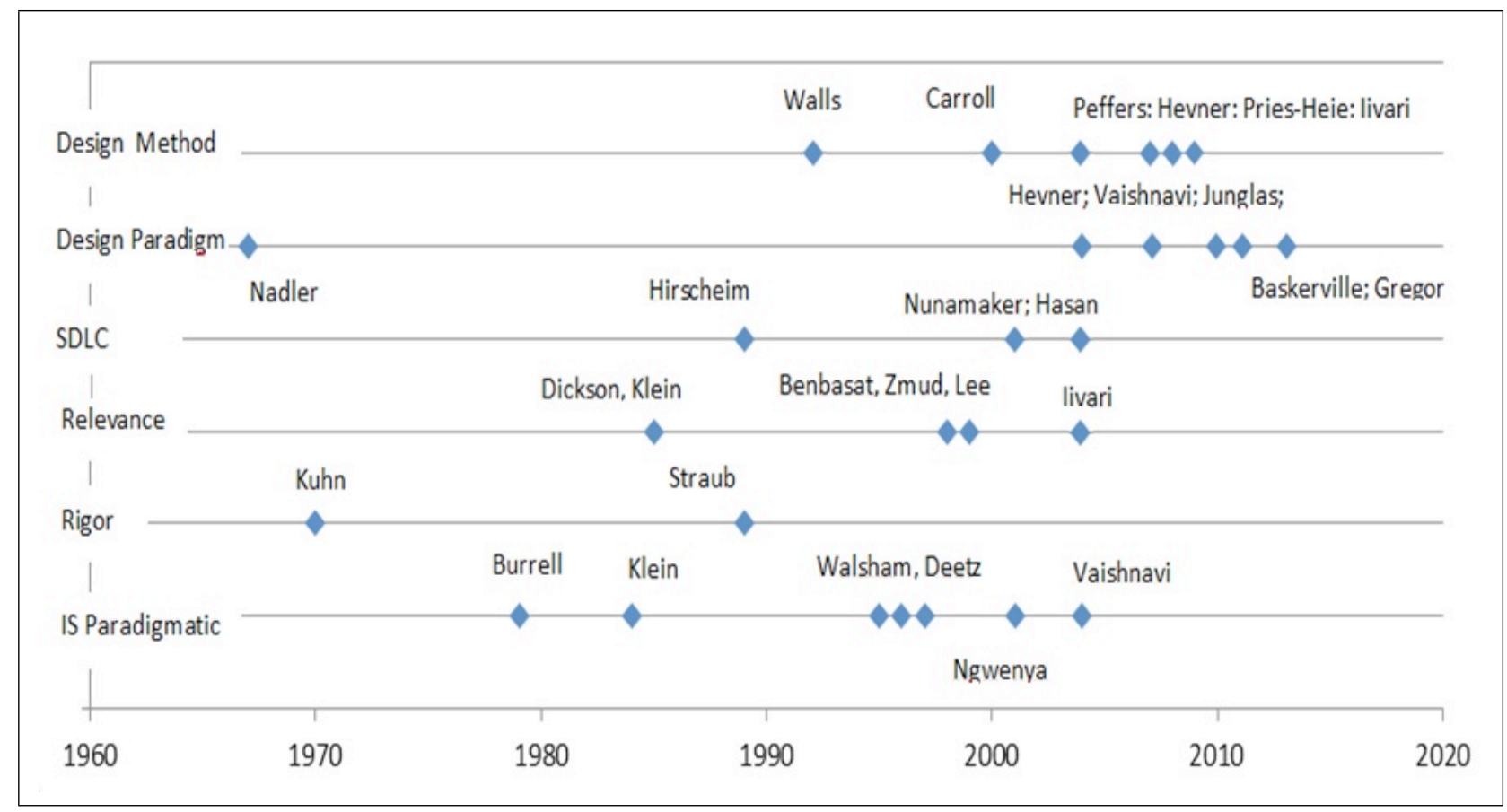

Figure 1: Overview on key activities leading to DSR. For each activity, only the primary author is shown.

paradigm". Furthermore, they claim that the following concern raised in the memorandum is not true for actual review practices in the European Journal of Information Systems (EJIS), Journal of the Association for Information Systems (JAISS), Information Systems Research (ISR) and Management Information Systems Quarterly (MISQ). In the effort to have their work published in these journals, researchers, and young researchers in particular, have no other choice but to comply with the journals' evaluation criteria for paper submissions. Basically, these criteria say that publications that provide statistical evidence of empirically identified characteristics of existing information systems are favoured over publications presenting innovative solutions that are considered highly beneficial for business.

Alan Hevner was appointed senior editor of MISQ and also published a paper with Shirley Gregor that focused on the positioning of DSR in IS 46]. With regard to DSR, the aim of the paper was to focus on levels of artefact abstraction and to structure a DSR article that emphasised significant contributions to the knowledge base.

The rigour and relevance emphasised by Hevner et al. 37. was already topical in earlier publications. The first attempts to use a phased approach for designing the artefact were introduced by authors such as Hirscheim and Klein 21. However, after 2004, there was more acceptance of DSR as a method when MISQ, one of the most respected journals in IS, published Hevner et al.'s 2004 paper on DSR as an acceptable approach 37.

During the data collection period of this study, DSR was still considered a novel and relatively unfamiliar research paradigm for Information Systems research in South Africa. This notion was supported by the data collected. Although DSR is growing, its widespread credibility will require further intersubjective work by the computing community, assimilating it into the community's discursive and research practices. Put simply, the success of DSR will remain a social accomplishment. The successful trajectory of DSR may depend largely on the kinds of representations currently circulating within the computing community [4].

\section{A SOCIAL REPRESENTATIONS ANALYTI- CAL FRAMEWORK}

\subsection{Conceptual overview}

Computing research has, for a long time, relied on traditional views within social psychology to study attitudes towards the unfamiliar (i.e. new technologies) normally using experimental or survey-based approaches [47, 48]. Although, these conceptual frameworks have been valuable in providing important insights into individual level factors, even those working within this paradigm have called for a wider understanding of the social relations and social environment in which such attitudes are formed. Instead of continuing with the prevailing overemphasis of atomistic approaches, this paper will assume a dialogical view of social reality - more specifically, that attitudes towards a social object such as DSR are conceived, constructed and communicated by social groups drawing from a variety of sources and through dialogical relationships [49.

The concept of social representations was introduced to the field of social psychology by the French scholar, Serge Moscovici, in 1961 [51, 52. Moscovici was interested in understanding how scientific knowl- 


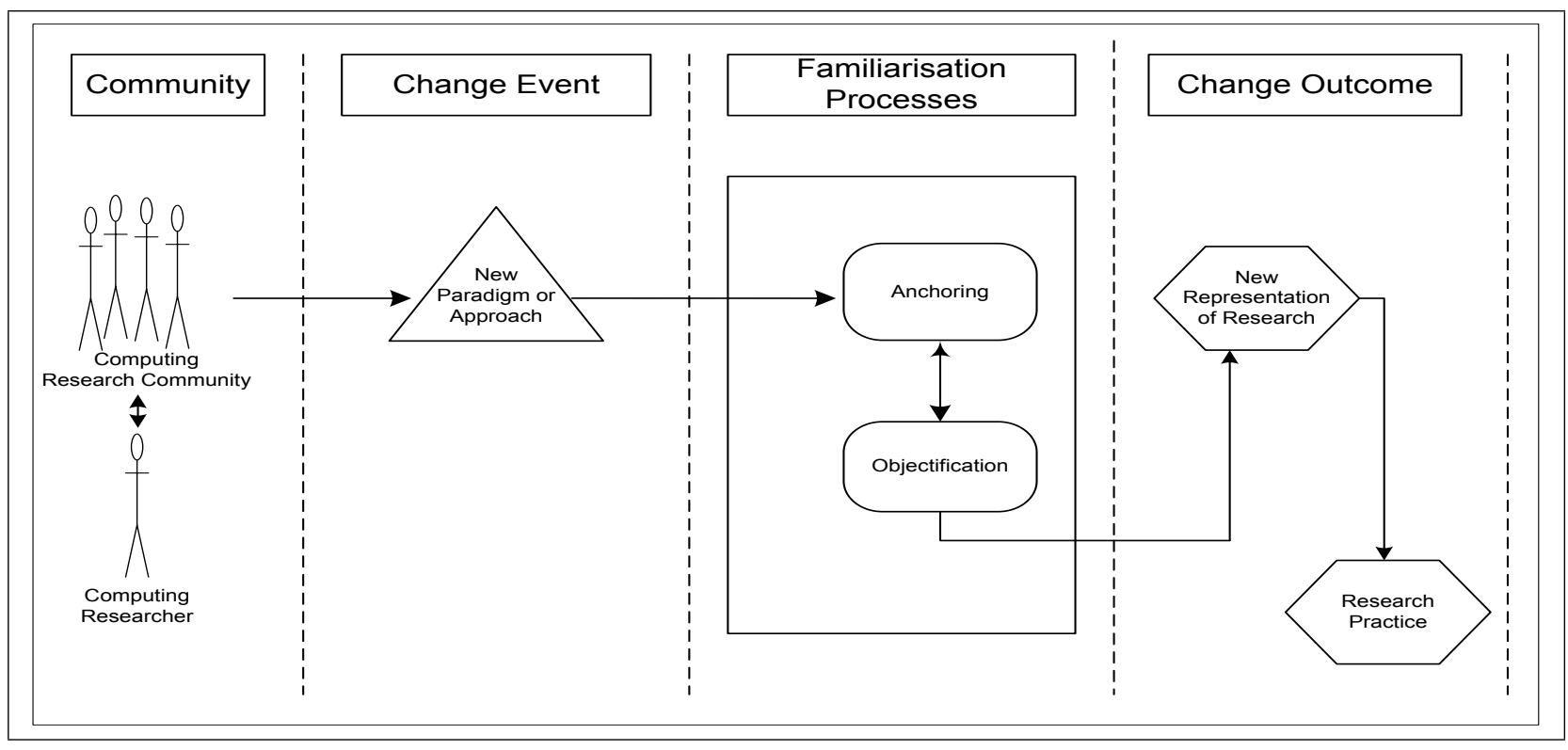

Figure 2: An SRT model of research familiarisation processes (adapted from Orfali [50]).

edge is diffused into common knowledge within society. The theory's starting point is that the relationship of a person with the world is invariably mediated by a layer of socially constructed and continuously evolving symbols or representations, which serve to render their world meaningful. In essence, social representations are people's ways of constituting the world [53. Moscovici defines social representations as

a system of values, ideas and practices with a twofold action: first, to establish an order which will enable individuals to orient themselves in their material and social world ... and secondly to enable communication to take place among the members of a community by providing them with a code for social exchange and a code for ... classifying ... the various aspects of their world and of their individual and group history. [54, p. 12]

Social representations enable people to make sense of their world, and to interact and communicate with other social actors. One of the important characteristics of social representations is that they serve to familiarise the unfamiliar, because it is the unknown or the unrecognised that poses a threat to shared and socially constructed realities [52]. New and unfamiliar events or phenomena that groups encounter in their daily lives can be seen as challenges that need to be symbolically and collectively coped with by group members. (See Fig. 2, which presents a very simplified schema of the process and consequences of forming a social representation.)

\subsection{Collectively elaborating an unfamiliar research object}

As depicted in Fig. 2, there are instances when the perceived gap between what people know and what they cannot understand leads to a lack of meaning, and a point of unfamiliarity appears. Representational work is set in motion to re-establish a sense of familiarity [54. Social representations can thus also be understood as 'collective elaborations' of unfamiliar phenomena or events [55]. Such phenomena or events become social reality by virtue of the representations that the community holds. Only by being represented by a group of people by means of familiar conceptual devices can an event or phenomenon become a social object that can be perceived, characterised and compared to other social objects, and used in language and action. SRT can help us examine the shared images and meanings through which people within a particular social group organise the world around them. It provides a rich vocabulary to examine the formation, change and content of these representations, and their relationship to people's actions.

\subsection{Central core and peripheral elements}

A social representation consists of a central core and peripheral elements - with the central core giving structure and meaning to a representation [56. The central core, or attitudinal component, is the one most resistant to change. For example, positivist researchers generally believe strongly in an objective reality. Effective transformation of a social representation is only possible if the central core itself is called into question. The peripheral elements of a representation act as a defense system, or 'shock absorber', as they may change without disturbing the central core [9]. For example, positivist researchers may adopt flexible approaches to collect data about objective reality, such as surveys and experiments. The peripheral elements also provide the interface between the central core and the concrete situation within which the representation operates and is elaborated on. Social representations can also be characterised as being bi-modal, that is, they are at once stable and rigid, because they are determined by the central core that is profoundly crystallised in the 
value system shared by group members [9]. At the same time, they are dynamic and permeable, because they integrate a wide variety of individual experiences that marks the evolution of individuals or groups.

\subsection{Consensus, differences and change}

Social representations are also polyphasic, suggesting that they may differ depending on which group a person belongs to. While social representations are shared by members of a particular community, they are not necessarily shared by members of other communities [57. People also have the ability to think about the same social object in contradictory terms in different situations [58. SRT is explicit about sociogenesis, where sociogenesis refers to the processes through which social representations are diffused via a community, as well as the historical processes through which such representations are transformed. Ontogenesis, on the other hand, refers to the processes by which people are already structured in terms of the social representations of their community or culture. Microgenesis refers to processes during social interactions where people may adopt a position distinct from those with whom they are interacting. This change in position may contribute to ontogenetic changes in an individual or sociogenetic transformations that result in the restructuring of social representations [58]. Social representations are also subject to temporal change as different groups start representing a social object in different ways according to their experiences, interactions and communication processes.

\subsection{Anchoring and objectification}

Anchoring and objectification are the two main processes through which social groups represent their reality [50]. In the case of anchoring, a new social object is anchored to pre-existing knowledge, and is assessed through the lens of a familiar object. Objectification is the process of integrating an object into social reality, thus acquiring its own place in the group's common sense reality. This new object may be tangible (e.g. the instantiation of an IT artefact) or highly abstract (e.g. the idea of an innovative design). These processes are dialectic in the sense that anchoring relates new objects to pre-existing ones, while objectification introduces new objects to social reality. Anchoring and objectification are mutually constitutive in the sense that a new object is usually first understood through anchoring and only then acquires its own place in the common sense reality of the community through objectification. Over time, through social interactions, this becomes part of the common knowledge shared among members of a community, where the social representation becomes a fairly stable product of the community's discourse 50].

The understanding of a new research paradigm depends on the social representations that correspond to a research community's stable and socially shared knowledge. This knowledge is represented in the researchers' elaborations and communication being used to make sense of and to act within their social context. The processes of anchoring and objectification should help us better understand how researchers become familiar with an unfamiliar social object such as DSR.

Table 1: A social representation analytical framework

\begin{tabular}{ll}
\hline SRT concepts & Definition \\
\hline Anchoring & To cope with the change, re- \\
& searchers are likely to anchor the \\
& new research paradigm or ap- \\
& proach to their personal or com- \\
& munity's pre-existing knowledge \\
& and beliefs. \\
\hline Objectification & Researchers are likely to use im- \\
& ages, rhetoric and metaphors to \\
& objectify the unfamiliar research \\
& paradigm or approach to what is \\
& already familiar, to make it more \\
& concrete or accessible to them- \\
& selves or their community. \\
&
\end{tabular}

\section{METHODOLOGY}

This research uses a social psychological analytical framework, depicted in Fig. 2, to investigate how members of a computing research community go about understanding a relatively unfamiliar research paradigm.

A social representations analytical framework assumes that such understandings are constructed through dialogue and social interaction. As such, qualitative data was more suitable for this research. Although individual interviews could also have been an effective method for collecting extensive insights, it would have limited the researchers' ability to provide participants with a natural and congenial community setting to interact with 49 .

The use of group interaction to probe the views of individuals via focus groups was a more effective approach to understand the dynamics of social representations within a research community [59]. Since social representations are rooted in the collective and symbolic life of a particular community, it was appropriate to investigate where, as computing researchers in an interactive, natural social setting, they had to take into account their colleagues' views in order to devise their own responses. Furthermore, dynamic group interaction was more likely to generate data and insights on a wide range of views and opinions that were not easily accessible using interviews. The informal dialogical approach afforded by a focus group discussion was expected to encourage group members to communicate their perspectives with others more openly.

\subsection{Data collection: Focus group procedures}

For the purpose of this research, it was important that participants were not selected randomly and that they belonged to an existing community. Many participants had a prior history as group members of South Africa's 
computing research community and shared a common culture with regard to their interests in computing research. Guests attending a DSR workshop conducted in Centurion, Pretoria, on 15 October 2012, volunteered to participate in the research. Overall, there were 45 participants across two discussion groups, of whom 25 were female and 20 were male. The participants were largely homogenous, comprising computing academics, with an average of 15 years' research experience. However, social units in the group also consisted of $\mathrm{PhD}$ candidates, as well as researchers in computer science, IS and human and computer interaction (HCI), which helped overcome slight concerns about the diversity of views. Their attendance of the workshop also suggested that they shared a common interest in the unfamiliar social object under consideration, namely DSR.

Participants were divided into two groups. On arrival at the discussion group location, they were seated and presented with a folder containing a pen and two A4 sheets of paper. After a brief introduction by the moderators (two of the authors) of each group, each participant was asked to turn to the first piece of paper in his or her folder, to reflect on his or her everyday experiences, and to write and/or draw whatever words and/or images came to mind when reading the words: "Design science research in computing". This activity was the catalyst for participant engagement and resulted in a subsequent verbal exchange of views about DSR using the different visual stimuli.

When an extended pause in the discussion was reached, the moderator asked each participant to turn to the second piece of paper in his or her folder and write and/or draw whatever words and/or images came to mind when reading the pre-printed words: "Design science research and traditional research paradigms. Do they complement each other?" Moderators only acted when strictly necessary. The ensuing discussion was allowed to flow so that the group members could decide on the relevant issues, debate meanings and oppose or reach consensus with each other, as they saw fit. Since the conversational strategies and processes of interaction of the groups were relevant to the research, the moderators made no special attempt to engage those group members who were reluctant to speak.

For the final step, the moderators waited for an extended pause in the discussion before asking participants to complete a short (one page) exit survey. The exit survey recorded socio-demographic information about their experience in academic research and years involved in DSR. Participants were also asked to rate their familiarity with the different research paradigms such as positivism, interpretivism and DSR. Both focus groups were videotaped and the recordings were later transcribed.

\subsection{Data analysis}

The text sketches and the transcripts of the group discussions were subjected to qualitative analysis. The thematic analysis was guided by a coding template (Table 4) and the researchers' understanding of the
SRT processes of anchoring and objectification. Each of the group transcripts and individual text sketches was subjected to a manual thematic analysis using the coding template with themes defined as patterned responses or meaning within the data set. A form of inter-rater reliability was sought by identifying areas of agreement and disagreement over coding between three of the researchers and an independent researcher. An academic blind to the purpose of the study coded 20 randomly chosen excerpts, assigning 18 to the same thematic categories the researchers assigned, yielding a $90 \%$ level of agreement.

The data gathered from the two focus group discussions and the individual text supplied by the participants were analysed using Fereday and MuirCochrane's 2006 guidelines for conducting a hybrid approach to deductive and inductive coding and theme development [60. The deductive analysis began with the development of a coding template 61. The coding template contained codes informed by the research question, as well as initial insights obtained from the literature study on computing paradigms and related fields. Six major sensitising coding categories were identified, including 'paradigm', 'process', 'methodological choice(s)', 'artefact', 'relevance' and 'rigour'. For each of these broad categories, a number of lower level codes were identified. For example, "paradigm" was broken down into five possible types: 'positivist', 'interpretivist', 'critical realism', 'pragmatic' and 'postmodern').

The next step in the analysis involved testing the applicability of these codes. This was done by coding two documents (the focus group transcripts and the individual text supplied by the participants), and assigning the predetermined codes from the coding template. As the researchers worked through the text line by line to assign the predetermined codes, they also assigned inductive codes to segment data where the units of meaning could not be appropriately captured by the predetermined codes. This allowed for new insights to emerge as these codes either constituted something new, or refined or extended the existing codes.

The researchers reviewed the assigned codes independently and jointly, looking for connections between them and paying attention to patterns in the data. At this point, the researchers began to identify and label themes, and cluster the themes. They eventually came up with higher order themes that captured the key dimensions and dynamics characterising a computing scholar's general representation of the design science paradigm. For example, the 'rigour' and 'relevance' of the 'IT artefact' was viewed as a key dimension that distinguished and characterised the theme underpinning the goals of DSR. Furthermore, the researchers performed a quantitative content analysis to establish the prevalence and robustness of the study's themes from these documents (Table 2). 


\subsection{Visual and metaphorical thematic analysis}

Gleeson's guidelines for visual thematic analysis were adopted 62. The researchers analysed the images iteratively, independently and jointly. To avoid restricting interpretations in the initial stages, the visual data were analysed independently of the coding template and textual data (both written and spokenduring the focus groups). Initially, a tentative set of visual themes that seemed to portray the images was recorded. A short descriptive note was also written for each theme that emerged. Only then were the coding template, illustrator's comments and focus group transcripts revisited to help refine the initial analysis. Remaining images were scanned again to see if the theme of the image under analysis applied to these as well. The search for themes was concluded when no further separate themes relevant to the research question emerged. The elements from the different images that best described the theme were eventually synthesised to form the study's key visual themes. The descriptions of the themes were examined to see if they captured any distinctive features of the image. The remaining themes were examined to establish their relationships to each other and to examine if they were connected by a higher order visual theme. In the next part of the analysis, the transcripts were read again to identify the use of metaphorical constructions and imagery deployed during the group discussions to objectify the new representations. See Table 2 for the main themes and evidence of their occurrences. Version 6.2 of ATLAS.ti - a qualitative research software tool - was used to store and analyse all the documents.

\section{RESULTS}

First, the researchers quantified the main coding themes from the drawing and association tasks to assess their occurrences (Table 2). Of the 90 completed word/image associations, the majority consisted of only words $(n=68)$ and a further 22 were a combination of words and drawings. None of the drawings were without words. A total of 548 statements were categorised. A number of these statements had more than one associated theme. In total, 892 codes were assigned.

The key themes from the deductive content analysis were 'research process', 'artefact', 'research paradigm', 'rigour of the research' and 'theory' (Table 2). These parent themes were derived from secondary themes. For example, the 'phase(s)' in a DSR project was/were inferred from the subphases mentioned, such as 'build' and 'evaluate' (see Table 4 for further clarity). Similarly, the notion of novelty as a secondary theme was evident when key themes, such as 'problem-solving', 'innovation' and other themes, such as 'researcher creativity', were analysed.

Second, the researchers drew on excerpts from the transcripts and examples of drawing and association tasks to illustrate the views and meanings that computing researchers associated with DSR and the conventional approaches to computing research practice.
Next, the familiarisation processes of anchoring and objectification were used to discuss how these themes played out during the focus group discussions.

\subsection{The complementary nature of DSR}

Overall, there was general agreement among participants that DSR had both complementary and distinctive associations with traditional forms of research. The three drawings provided in Fig 3 are representative exemplars that capture the similar and unique manner in which researchers objectified their conceptions of DSR.

Table 2: Codes and frequency distribution

\begin{tabular}{lrrr}
\hline Codes & Freq & Freq (\%) & C. Freq (\%) \\
\hline Process & 133 & 14.91 & 14.91 \\
Artefact & 101 & 11.32 & 26.23 \\
Paradigm & 92 & 10.31 & 36.55 \\
Rigour & 79 & 8.86 & 45.40 \\
Theory & 68 & 7.62 & 53.03 \\
Problem-solving & 57 & 6.39 & 59.42 \\
Relevance & 42 & 4.71 & 64.13 \\
Phase(s) & 38 & 4.26 & 68.39 \\
User & 26 & 2.91 & 71.30 \\
Computing discipline & 23 & 2.58 & 73.88 \\
Reasoning & 21 & 2.35 & 76.23 \\
Design & 15 & 1.68 & 77.91 \\
Goal-oriented & 14 & 1.57 & 79.48 \\
Innovation & 13 & 1.46 & 80.94 \\
Contextual & 10 & 1.12 & 82.06 \\
Iterative & 10 & 1.12 & 83.18 \\
Scientific & 9 & 1.01 & 84.19 \\
Build & 8 & 0.90 & 85.09 \\
Other* & 143 & 16.03 & 100.00 \\
TOTAL & $\mathbf{8 9 2}$ & $\mathbf{1 0 0 . 0 0}$ & $\mathbf{1 0 0 . 0 0}$ \\
\hline
\end{tabular}

* 'Other' includes 'researcher skill', 'researcher creativity', 'communication', etc.

The first drawing shows the participant anchoring his or her understanding of DSR to traditional research approaches. The drawing depicts a complementary relationship between DSR and traditional research paradigms. This participant used a basic system map to depict DSR as 'part of the whole' of research paradigms:

I believe they sort of complement each other, or supplement each other or something like that ... but this one makes up the whole circle together.

This participant also chose to depict an imaginary spatial boundary between DSR and traditional approaches, as opposed to making the overlaps between the two explicit, implying that the participant is also emphasising a distinction between DSR and traditional research approaches. It is also interesting that the two research subsystems are split into equal proportions, even though DSR is still relatively nascent when compared to the other major paradigms.

The second drawing, with a number of bidirectional arrows, objectifies a more complex interrelationship be- 


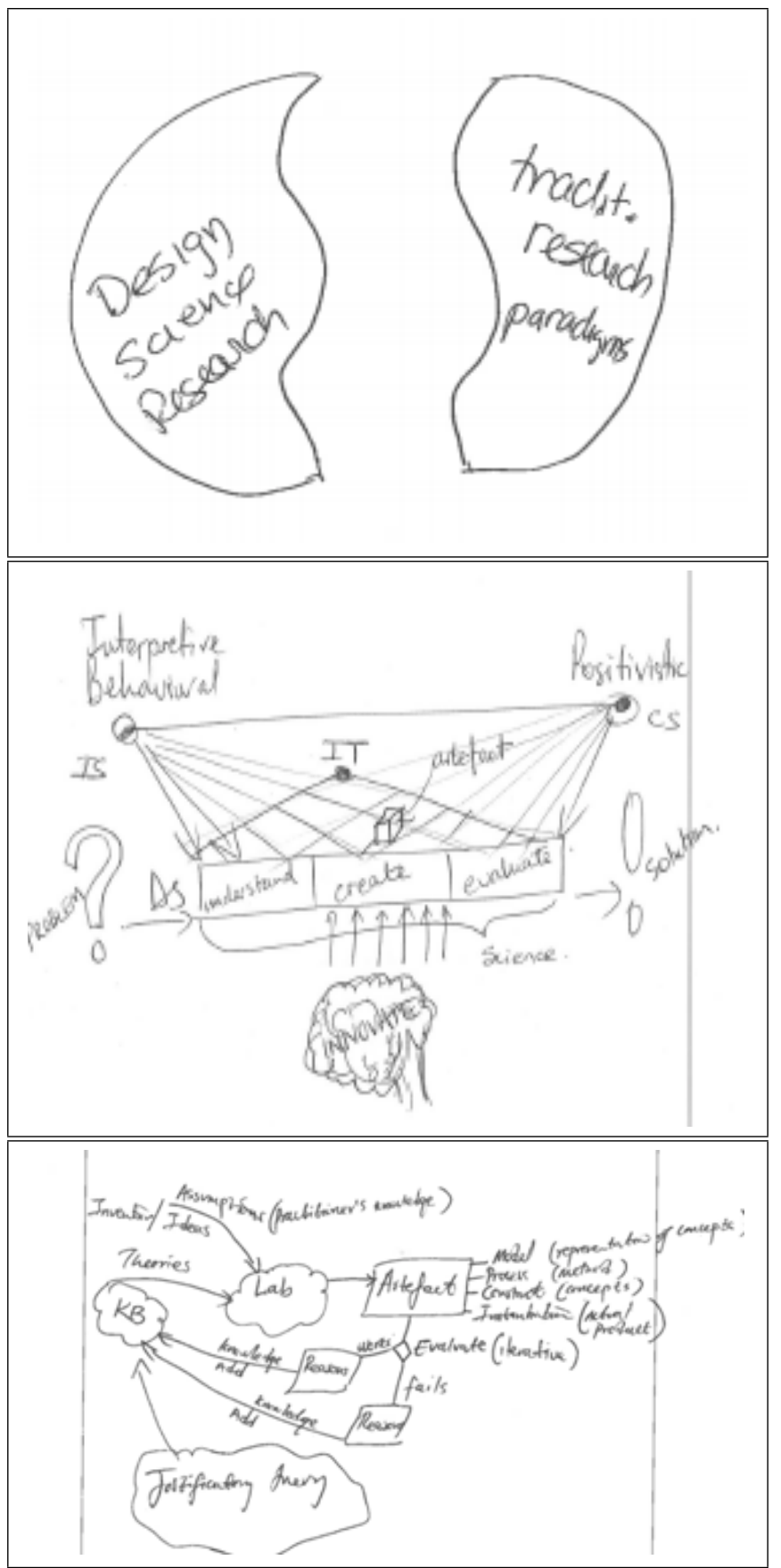

Figure 3: Three divergent examples of DSR perspectives from the drawing task

tween traditional forms of research and DSR. (Table 4 provides more details about this and other elements of images that were used to objectify the different concepts in DSR.) This participant uses polar opposites to show the distinctive nature of interpretive and positivist research and their association with the different disciplines in computing by anchoring information systems more closely to interpretive and a specific type of positivist research (behavioural research) and computer science more closely to positivist research. At the apex of the triangle is information technology (IT) implying that the problem-solution space involves an IT solution. The area of the triangle represents the IT environment and the small 3D box found at the specific coordinates within this triangle depicts the particular IT design artefact that is required to solve a particular problem. The arrows indicate the extent to which this particular problem space is influenced by the different computing disciplines and research paradigms. Their criss-crossing relationships demonstrate the complementary use of traditional approaches to solve unique design-related problems.

The participant who drew the second drawing commented on his complementary perspective:

I tried drawing it as a process of where we've got a problem, working towards a solution on the other end. And then essentially I see three phases - understanding, creating and evaluating - inside that. And then I tried drawing that in the understanding phase. One draws (well, in all the phases, really) from all the different paradigms that we've got in research in general. My feeling, and certainly what I observe if I look at it, is that people tend to draw a little bit more on the interpretive side in the understanding and a little bit more on the positivistic side in the evaluation, but that's a personal perception from my side.

Similarly a number of participants defined DSR by anchoring it to their conventional research practice and relating to it in their own terms (see Table 4 for more details). For instance, a number of participants associated DSR with a particular paradigm. During the focus group sessions, one participant stated

I think, my perception is that ... the empirical looks at multiple scenarios and measures them ... and design science is time-based, similar to interpretive. It looks at one scenario, but over a time period ... .

In the same way, another participant associated DSR with the action research approach:

... for my diagrams here I started with a fairly simplistic action research diagram which involved longitudinal reflection.

The following participant, while associating DSR with the action research approach, differed from the previous participant by linking DSR to a pragmatic philosophical orientation:

I know in action research they pretty much stated that their paradigm is pragmatism, that's part of the argument, it's not positivism, it's not interpretivism, and in a way this is to me the closest to action research. A number of participants also anchored DSR to their field or discipline by sometimes emphasising differences instead of focusing on commonalities alone. For instance, participants noted the distinction between general research in software development and the rigour emphasised in DSR. One participant stated

... some reviewers have come back and said that it looks like they're (research students) developing a tool rather than doing research. And I've always said to my students, you know, research is not a software engineering project. 
Table 3: Evidence of anchoring, using the major sensitising coding categories and themes

\begin{tabular}{|c|c|c|}
\hline $\begin{array}{l}\text { Major anchoring } \\
\text { categories for } \\
\text { representation }\end{array}$ & $\begin{array}{l}\text { Evidence of anchoring within existing knowledge } \\
\text { and belief(s) }\end{array}$ & \\
\hline Paradigm & $\begin{array}{l}\text { A world view of a scientific community characterised by } \\
\text { a unique ontological, epistemological and methodological } \\
\text { position. The design science paradigm was characterised as } \\
\text { having a practical problem-solving orientation with empha- } \\
\text { sis on the building and evaluation of an IT artefact. } \\
\text { However, many respondents believe that this could be } \\
\text { achieved using a multi-paradigmatic world view in that } \\
\text { this type of research could accommodate both or either a } \\
\text { positivist or an interpretivist approach. A few believed that } \\
\text { it was exclusively positivist in its orientation. }\end{array}$ & $\begin{array}{l}\text { "Differs from traditional } \\
\text { paradigms" }\end{array}$ \\
\hline Process & $\begin{array}{l}\text { Research is generally viewed as a systematic process, } \\
\text { backed by data, to answer a question or solve a problem. } \\
\text { The design science process was characterised as having an } \\
\text { iterative, cyclical nature. }\end{array}$ & $\begin{array}{l}\text { "Iterative process, cyclical." } \\
\text { Also see illustration (Fig. } 2 \text { ) }\end{array}$ \\
\hline $\begin{array}{l}\text { Methodological } \\
\text { choices }\end{array}$ & $\begin{array}{l}\text { A methodological choice is generally informed by a } \\
\text { paradigmatic stance that privileges the collection of a } \\
\text { particular data type or data analysis procedure. Some } \\
\text { respondents claimed that design science embraces } \\
\text { methodological pluralism. However, a few suggested that it } \\
\text { was better suited for experimentation and quantitative } \\
\text { approaches, such as statistical analysis. }\end{array}$ & $\begin{array}{l}\text { "Mixed methods is a } \\
\text { catchword" } \\
\text { "What came to mind is a kind } \\
\text { of experimental research" }\end{array}$ \\
\hline Phase & $\begin{array}{l}\text { A phase in the research process is generally viewed as a } \\
\text { common and closely connected set of activities that work } \\
\text { together to achieve a particular goal and set of objectives. } \\
\text { For instance, the respondents identified evaluation as a } \\
\text { distinctive phase in a DSR project. }\end{array}$ & $\begin{array}{l}\text { "Evaluation of artefact" } \\
\text { "Evaluation of solution" }\end{array}$ \\
\hline Artefact & $\begin{array}{l}\text { Simon [29] defines an artefact as something that is artificial, } \\
\text { or constructed by humans, as opposed to something that } \\
\text { occurs naturally. Orlikowski and Baroudi [24] view the IT } \\
\text { artefact as a collection of material and cultural properties } \\
\text { packaged in some socially recognisable form, such as } \\
\text { hardware and software. Hevner et al. [37] refer to design } \\
\text { artefacts produced by DSR as constructs, models, methods } \\
\text { and instantiations. Many respondents expressed varied and } \\
\text { distinctive definitions of the artefact. }\end{array}$ & $\begin{array}{l}\text { "Bundles of hardware, soft- } \\
\text { ware, etc." } \\
\text { "Conceptual artefact" } \\
\text { "Creating an artefact" } \\
\text { "Creating models" } \\
\text { "Database" } \\
\text { "Applications" } \\
\text { "Design solution" }\end{array}$ \\
\hline Relevance & $\begin{array}{l}\text { Benbasat, Zmud and Price [30] posit three dimensions of IS } \\
\text { research relevance: interest to IS/IT professionals, } \\
\text { applicability as an indication of utility, and currency of } \\
\text { problems addressed. Kuechler \& Vaishnavi } 63 \text { add } \\
\text { accessibility of research to practitioners. Many respondents } \\
\text { felt that DSR directly addresses the relevance gap in } \\
\text { computing research. }\end{array}$ & $\begin{array}{l}\text { "Investigating a real-world } \\
\text { problem" } \\
\text { "Practical application" }\end{array}$ \\
\hline Rigour & $\begin{array}{l}\text { Kuechler and Vaishnavi [63] define rigorous research as } \\
\text { research that emphasises methodological correctness. A } \\
\text { number of respondents believe that DSR makes it possible } \\
\text { for rigour and relevance to coexist. }\end{array}$ & $\begin{array}{l}\text { "Creating rigour in design and } \\
\text { evaluation of the artefact" } \\
\text { "DSR assists with defending } \\
\text { the outputs" }\end{array}$ \\
\hline
\end{tabular}


Table 4: Evidence of objectification using images and metaphorical constructions

\begin{tabular}{|c|c|c|c|}
\hline SRT concepts & Definition & $\begin{array}{l}\text { Evidence of objectification to make } \\
\text { the new paradigm's representation } \\
\text { more concrete and accessible }\end{array}$ & Elements of images \\
\hline $\begin{array}{l}\text { Objectification } \\
\text { using images }\end{array}$ & $\begin{array}{l}\text { Nature of image/ text } \\
\text { used to objectify DSR } \\
\text { to what is already fa- } \\
\text { miliar, to make unfa- } \\
\text { miliar or controversial } \\
\text { concepts more concrete } \\
\text { or accessible }\end{array}$ & $\begin{array}{l}\text { Conventional research in IS is often con- } \\
\text { veyed as a spiral or helix. Many partici- } \\
\text { pants depicted DSR as having an iterative, } \\
\text { cyclical nature using a basic flow diagram. } \\
\text { Some participants depicted the social activ- } \\
\text { ities involved in the research process. For } \\
\text { instance, the creative and problem-solving } \\
\text { activities by the researcher, the participa- } \\
\text { tion of the end user and the uses of the } \\
\text { innovative artefact. } \\
\text { Other participants captured similar con- } \\
\text { cepts using text. Some participants de- } \\
\text { picted the project activities involved in the } \\
\text { research process. For instance, they fo- } \\
\text { cused on the phases and the relationship } \\
\text { between the different phases of the research } \\
\text { process (also see illustrations in Figure } 3 \text { ) }\end{array}$ & $\begin{array}{l}\text { Systematic flow of steps, } \\
\text { boxes, arrows to depict } \\
\text { directionality or feedback } \\
\text { loop } \\
\text { Large cloud, question } \\
\text { mark, a box, human brain } \\
\text { to depict elements such } \\
\text { as problem-solving and an } \\
\text { innovative IT artefact }\end{array}$ \\
\hline $\begin{array}{l}\text { Objectification } \\
\text { using metaphors }\end{array}$ & $\begin{array}{l}\text { Nature of metaphors } \\
\text { used to objectify DSR } \\
\text { to what is already fa- } \\
\text { miliar, to make unfa- } \\
\text { miliar or controversial } \\
\text { concepts in DSR more } \\
\text { concrete or accessible }\end{array}$ & $\begin{array}{l}\text { Some participants objectified the unfamil- } \\
\text { iar using abstract metaphors, while others } \\
\text { drew on more concrete analogies. } \\
\text { "Finding solutions to problems } \\
\text { doesn't happen in a singular de- } \\
\text { fined space, it's always part of a } \\
\text { bigger context in which there are } \\
\text { stakeholders and decision-makers, } \\
\text { and problems and solutions, and } \\
\text { they all mix up. They don't nec- } \\
\text { essarily meet nicely, and that was, } \\
\text { metaphorically speaking, what } \\
\text { the value of the garbage can idea } \\
\text { was." } \\
\text { "I drew sort of bridges between } \\
\text { the two. From a design science } \\
\text { perspective, it wants to draw on } \\
\text { traditional science, because of the } \\
\text { restrictions for the traditional sci- } \\
\text { ence, it doesn't have to be an arte- } \\
\text { fact development ..." } \\
\text { "I just want to second the thought } \\
\text { that she was raising, I think } \\
\text { what's unique from design science } \\
\text { is the soul and that soul is an arte- } \\
\text { fact and that I think is unique to } \\
\text { design science." }\end{array}$ & $\begin{array}{l}\text { From abstract examples: } \\
\text { "Soul" } \\
\text { "Recombination" } \\
\text { "Journey" } \\
\text { To more concrete exam- } \\
\text { ples: } \\
\text { "Mixture" } \\
\text { "Bridge" } \\
\text { "Garbage can" } \\
\text { "Broken eggshell" }\end{array}$ \\
\hline
\end{tabular}


Similarly, another stated:

From the computer paradigm, I think it's software engineering on steroids; adding research to software engineering.

Some participants discussed the problem-solving or solution orientation of DSR with an added emphasis on "real-world" problems and the artefact. For instance, one participant commented:

My basic thing is, in design science, whether even in design research or design science, it's a business industry-oriented problem. You must have a problem that is being solved or addressed by means of an artefact. Those two things to me are core when we talk about design science.

Other participants also emphasised the problemsolving orientation and the artefact, but drew attention to the rigour and multiple iterations involved in the DSR research process:

My understanding of DSR is that ... we try and find out which of the existing models are applicable to the problems that you need to solve right now, you select what you think is applicable, then you design a prototype solution for solving a problem, and then you evaluate your design, you reflect on it, how is it applicable to the problem at hand and then you look back on the original design and if you think that this does not solve your problem, you re-evaluate. You basically go through those steps until you think you have a solution.

Overall, there was a high degree of commonality during the focus group discussion across participants in terms of the way in which DSR's rigorous problemsolving research approach was anchored (see Table 3) and objectified (see Table 4). Rigour appeared to be a core representation shared by the different groups. It appears to be non-negotiable within the different computing disciplines and the overall computing community.

Across the groups, DSR was also commonly described as being more connected to creativity and innovation than conventional research approaches. For instance, the participant who drew the second diagram added:

I tried drawing it as a process of where we've got a problem, working towards a solution on the other end. And then essentially I see three phases: understanding, creating and evaluating, inside that ... I tried drawing a brain to show that innovation is really the creation part, but then I realised that I am not an artist. (laughter)

Table 4 provides more details about the nature of the metaphors that were used to objectify the major concepts in DSR.

\subsection{Distinctive objectifications of DSR}

The results of the association task and group discussions revealed that the core representations of DSR were largely shared by the subjects. However, the three drawings presented in Fig. 3. while depicting this commonality in the DSR representations at an abstract level, also pointed to differences and inconsistencies at a detail level of analysis. The evidence seems to suggest that, across the computing community, DSR at this stage is associated with peripheral representations, while different core trajectories seem to be developing within a particular community.

The three participants whose diagrams are mentioned come from three different research communities (HCI, software engineering and computer science), as well as different research institutions. The differences in the drawings reflect that their understandings are anchored to specific objectives, practices and experiences, and as a consequence they seem to already be developing their distinctive world views of DSR. For instance, both Drawing 2 and Drawing 3 are similar in how they objectify the importance of the 'evaluate' phase in a DSR project, and equally point out the importance of the IT artefact (see Table 3). However, when compared to the first two drawings, the third drawing is more explicit in depicting the influence of academic discourse in framing the participant's understanding. For example, this participant draws directly from the work of Hevner, Marck, Park and Ram 37 to depict a more formal understanding of the various classes of the IT artefact and to demonstrate the importance of using theory ('justificatory theory') and developing theory, adding to the knowledge base (KB) in DSR. Another participant emphasised the importance of a theoretical contribution, stating:

I see the theoretical contribution coming from testing the artefact in the practical situation and then learning from what you observe and see happening, and building a more general IS design theory from that instance, and coming up with a generalised theory that's more applicable to a wider context.

The third drawing also shows a more complex interaction between the different components to design an artefact. This participant uses systems modelling akin to models depicting problem-solving for emergent systems in soft systems analysis 64. The DSR process is objectified as a collection of parts that interact to produce the properties of the whole. A key feature in this diagram is the representation of the emergent quality of the KB. The participant uses arrows, a feedback loop and a decision point, implying that the interaction between a number of separate components or elements, such as the research problem, justificatory knowledge theory and artefact evaluation processes, combine to develop the ongoing KB [39]. This participant also pays specific attention to the laboratory environment as a key actor in his/her system depiction.

\subsection{DSR anchoring issues}

The top two most-coded terms in Table 2 are 'process' and 'artefact'. The high prevalence of these terms in the text and discussions demonstrates the strong 
influence from more familiar research disciplines on anchoring. However, these and some of the other themes cannot be regarded as part of a core representation as they are not depicted in a rigid or established manner.

Research paradigms are expected to have, as their core, a clear process description of how to perform a research project under that paradigm. However, the initial papers on DSR, such as Hevner et al. 37. and Gregor and Jones 39, do not prescribe a process for performing DSR. While Peffers et al. [41] offer some process guidance, the DSR literature provides few definitive processes for performing DSR. Thus, we find that researchers new to DSR have an expectation, predicted by anchoring, that a well-defined DSR process is presented in the literature and ready for use by researchers. It is not.

Another important area of contestation is the meaning and use of the term 'artefact' (see Table 3). Although the meaning of the design artefact has evolved over the years, and researchers have attempted to clarify this concept [65], multiple representations still dominate the computing field. For instance, one participant argued:

Whether it's positivist, interpretivist or critical, I think it could be any of those, it depends on the stance that you take as a design science researcher. If you believe that the artefact is a technical system, you might take a positivist perspective, if you view it as a social system, you carry out your design science from an interpretive perspective, however you perceive the artefact.

Meanwhile another participant had a different view, but acknowledges the existence of other representations:

Because my view of design research is always the IT artefact, I perceive it to be the IT artefact. Some people view the artefact as much broader than that.

These flexible and consensual characteristics of the artefact depicted here suggest that DSR researchers, at least as members of a broader community, are willing to view the artefact as a peripheral element. So, while the findings generally revealed commonality among the participants, the non-consensual character of participants' representations of DSR as themes such as 'process' and 'artefact' at a finer level of analysis is evidence of how different individuals and research communities, shaped by their traditional paradigms, within the computing field can sometimes construct distinctive meanings about a relatively new research paradigm's core and peripheral concepts.

\section{DISCUSSION}

This research used SRT to explore the symbolic associations computing scholars made about DSR during a focus group workshop. Visual methods formed a key part of the methodological tools used to investigate the social aspects of this fairly novel research practice, such as how scholars make sense of and assign meaning to a fairly new research paradigm. Image-making through drawing and association tasks, and verbal discussions revealed scholars' core representation of DSR as a

- novel,

- problem-solving, and

- rigorous

artefact producing way of doing research in order to develop design theory in computing.

Prior to the processes of objectification, many participants drew on traditional forms of research to serve as anchors to understand DSR. Direct links to 'action research' and complementary links to positivist and interpretivist research traditions were made. The findings confirm that a new object (new research paradigm) is being anchored to pre-existing knowledge about academic research and is being assessed through these lenses. However, given the relative nascence of DSR and differences in social constructions, inconsistencies in the representation of different participants were also evident.

The findings suggest that, while researchers may share the dominant conceptions of DSR, a core representation of DSR does not exist. Researchers appear to be developing distinctive peripheral conceptions that are aligned to their communities with their specific objectives, practices and experiences. The idea that these different communities are developing different conceptions about the same object (e.g. IS professionals vs. computer science professionals in DSR) suggests that the understanding of DSR could sometimes contradict existing formal representations presented in the academic body of knowledge. These differences in social representations can translate into misunderstandings and miscommunications if members of the different computing disciplines or different research communities attempt to collaborate on a common DSR project.

The focus of this research was to use the concepts of anchoring and objectification to investigate how researchers construct their understanding of DSR. As mentioned, there are two distinct contributions from the investigation. The first is the indication that previous knowledge influences the view of DSR. The second is that researchers, in some cases, do not really understand the current literature and underlying theoretical underpinning of DSR. The main recommendation of this research is that more engagement with DSR is needed on different levels, and that it should not be used in a project without researchers understanding DSR. For the DSR community, researchers also have a responsibility to engage in activities related to DSR and to suggest doing so from the viewpoint of sharing more on the theoretical underpinning of DSR, being involved in facilitation activities, being involved in dissemination activities, collaborating with researchers involved in DSR, engaging in research projects that use a DSR approach, and establishing a community of researchers that can engage more in discussions on DSR.

The recommendations with regard to building DSR as a research method are summarised below: 
Theoretical underpinning: It is recommended that seminal articles and books that are widely cited (like some of those cited here) and deemed by experts to be substantially influential to the field should serve as the foundation for the development of researchers' DSR knowledge and be included in research curricula for researchers involved in postgraduate studies.

Facilitation activities: It is proposed that special doctoral seminars led by local or international experts in DSR are held to facilitate the development of students' research ideas and to build the local DSR community. Academic workshops that are inclusive of the different computing disciplines and examine DSR concepts and approaches can also be useful.

Dissemination activities: It is recommended that editors of local computing journals and conference organisers discuss the inclusion of special calls and special tracks to facilitate ongoing discourse [2].

Collaborating: It is proposed that interactive discussions between and within institutions could create a common understanding of and advancement in DSR.

Engaging: It is believed that the only way to truly understand the concepts and goals of DSR is to participate in a DSR research project. Researchers from all disciplines are encouraged to identify research goals to improve the effectiveness of relevant artefacts in their fields. The performance of build-and-evaluate activities in a DSR project will provide a better understanding of the rigour and relevance of the research paradigm.

Community: The establishment of a DSR community should also be a step towards establishing DSR as one of the dominant approaches for doing research. For managing all of the above, research leadership, participation and interaction are required, which are believed to reside in the local computing academic community.

Unlike conventional SRT research that studies the social nature of knowledge depicted by laypersons, this research demonstrates how professional researchers from different research communities - in this case, within the computing field - also represent new knowledge in various ways. Not surprisingly, this challenges the assumption that the scientific community can have consensual views about a new paradigm, especially in its early phase of development.

Furthermore, the polyphasic nature of social representations implies that the relationships among communities should be taken into consideration when developing or promoting a new research paradigm. These relationships and, in particular, the balance of power among communities, are likely to influence the representations of the various communities, as well as the overall dominating representation of DSR that may emerge within the computing field. For instance, some communities may believe that DSR is only applicable in a laboratory context or is biased towards a positivist paradigm. If this is perceived to be the case with DSR, then the computing community's inability to change some of these limiting mainstream representations may hinder the further development of DSR.

This research suggests that the experiences of researchers and their knowledge of DSR will depend on the DSR discourse and knowledge within the communities to which they belong. This can either limit or broaden the researcher's understanding of DSR. One thing is certain - the representations of DSR will evolve and change over time. If computing professionals from the various disciplines are to work together on common yet tricky design problems, it is important that they share similar core understandings of paradigms, such as DSR. SRT might be useful in pointing out those misunderstandings that prevent computing disciplines from changing and cooperating with each other.

\section{CONCLUSION}

The present research used SRT to investigate how researchers familiarised themselves with the relatively novel and unfamiliar DSR paradigm. The study has identified the salient social representations that computing research professionals use to depict and discuss DSR. In doing so, it confirms that researchers are familiar with the core academic discourse within DSR: a discourse that emphasises the rigorous, practical problem-solving nature of DSR, and one that focuses on building and evaluating an IT-based artefact. In doing so, it contributes towards design theory [39].

This research also points out that it is possible to stimulate the learning of new paradigms within the computing community. Furthermore, it points out how knowledge and common ground about DSR that draws on pre-existing knowledge can result in the formation of new social representations within a computing research community. Yet, while DSR calls for a major reorientation to computing research, the mainstream approaches within computing research are unlikely to change overnight. The views of antagonistic computing research groups - for instance, groups that resist DSR as they either see it as a threat or as being less prestigious when compared to their existing personal research preferences or their research community's identity - remain a key question for future research. Without such explorations in anchoring and objectification, it will be difficult to understand how new knowledge becomes part of - or fails to become a part of - a researcher's or research community's domain and whether these changes in representations actually translate into changes in research practice.

The nuanced findings of this research also suggest that qualitative research in computing in general can benefit from the use of visual images instead of relying on words alone. Lastly, the enhanced understandings about research provided by SRT can be used to direct efforts more appropriately within the computing community to broaden knowledge generation that benefits the larger society. 


\section{ACKNOWLEDGEMENTS}

We thank the National Research Foundation (NRF) for supporting the data-collection activities through the Knowledge Development Fund (KFD). Thank you to all participants for your input during the datacollection activities and Prof Nixon Ochara for your involvement as a critical reviewer to verify the data analysis.

\section{REFERENCES}

[1] A. Pickering. "From science as knowledge to science as practice". In A. Pickering (editor), Science as practice and culture. University of Chicago Press, 1992.

[2] R. Naidoo, A. Gerber and A. van der Merwe. "An exploratory survey of design science research amongst South African computing scholars". In Proceedings of the South African Institute for Computer Scientists and Information Technologists (SAICSIT) conference, pp. 335-342. ACM, 2012. DOI http://dx.doi.org/ 10.1145/2389836.2389876.

[3] P. L. Berger and T. Luckmann. The social construction of reality: A treatise in the sociology of knowledge. Penguin UK, 1991.

[4] B. Latour. Science in action: How to follow scientists and engineers through society. Harvard university press, 1987.

[5] T. J. Pinch and W. E. Bijker. "The social construction of facts and artefacts: Or how the sociology of science and the sociology of technology might benefit each other". Social studies of science, pp. 399-441, 1984. DOI http://dx.doi.org/10.1177/ 030631284014003004

[6] S. Moscovici. "The phenomenon of social representations". In R. Farr and S. Moscovici (editors), Social representations. Cambridge: Cambridge University Press, 1984.

[7] A. Contarello and M. Sarrica. "ICTs, social thinking and subjective well-being-The internet and its representations in everyday life". Computers in human behavior, vol. 23 , no. 2 , pp. 1016-1032, 2007. DOI http: //dx.doi.org/10.1016/j.chb.2005.08.013

[8] U. Gal and N. Berente. "A social representations perspective on information systems implementation: Rethinking the concept of 'frames"'. Information technology $\&$ people, vol. 21, no. 2, pp. 133-154, 2008. DOI http://dx.doi.org/10.1108/ 09593840810881051

[9] S. D. Pawlowski, E. A. Kaganer and J. J. Cater. "Focusing the research agenda on burnout in IT: Social representations of burnout in the profession". European journal of information systems, vol. 16, no. 5, pp. 612-627, 2007. DOI http://dx.doi.org/10.1057/ palgrave.ejis.3000699

[10] E. Vaast, R. Boland Jr, E. Davidson, S. D. Pawlowski and U. Schultze. "Investigating the 'knowledge' in knowledge management: A social representations perspective". Communications of the association for information systems, vol. 17, no. 1, p. 15, 2006.

[11] F. Grinnell. Everyday practice of science: Where intuition and passion meet objectivity and logic. New York, NY: Oxford University Press, 2009.
[12] T. S. Kuhn. The structure of scientific revolutions. University of Chicago press, 2012. DOI http://dx.doi. org/10.7208/chicago/9780226458144.001.0001

[13] M. Wade and J. Hulland. "Review: The resourcebased view and information systems research: Review, extension, and suggestions for future research". MIS quarterly, vol. 28, no. 1, pp. 107-142, 2004.

[14] D. Robey and M. Newman. "Sequential patterns in information systems development: An application of a social process model". ACM transactions on information systems (TOIS), vol. 14, no. 1, pp. 3063, 1996. DOI http://dx.doi.org/10.1145/214174. 214178

[15] J. Mingers. "Combining IS research methods: Towards a pluralist methodology". Information systems research, vol. 12 , no. 3, pp. 240-259, 2001. DOI http: //dx.doi.org/10.1287/isre.12.3.240.9709.

[16] D. Robey. "Research commentary: Diversity in information systems research: Threat, promise, and responsibility". Information systems research, vol. 7, no. 4, pp. 400-408, 1996. DOI http://dx.doi.org/ $10.1287 /$ isre.7.4.400

[17] University of Cambridge. "Diploma in computer science", 2012. URL http://www.cl.cam.ac.uk/ admissions/diploma/.

[18] G. W. Dickson, I. Benbasat and W. R. King. "The MIS area: Problems, challenges, and opportunities". ACM SIGMIS, vol. 14, no. 1, pp. 7-12, 1982.

[19] G. Burrell and G. Morgan. Sociological paradigms and organisational analysis, vol. 248. London: Heinemann, 1979.

[20] H. K. Klein and K. Lyytinen. "The poverty of scientism in information systems". Research methods in information systems, pp. 131-161, 1985.

[21] R. Hirschheim and H. K. Klein. "Four paradigms of information systems development". Communications of the ACM, vol. 32, no. 10, pp. 1199-1216, 1989. DOI http://dx.doi.org/10.1145/67933.67937

[22] S. Deetz. "Crossroads-describing differences in approaches to organization science: Rethinking Burrell and Morgan and their legacy". Organization science, vol. 7, no. 2, pp. 191-207, 1996. DOI http: //dx.doi.org/10.1287/orsc.7.2.191.

[23] V. Venkatesh, S. A. Brown and H. Bala. "Bridging the qualitative-quantitative divide: Guidelines for conducting mixed methods research in information systems". MIS quarterly, vol. 37, no. 1, pp. 21-54, 2013.

[24] W. J. Orlikowski and J. J. Baroudi. "Studying information technology in organizations: Research approaches and assumptions". Information systems research, vol. 2, no. 1, pp. 1-28, 1991. DOI http: //dx.doi.org/10.1287/isre.2.1.1

[25] G. Walsham. "The emergence of interpretivism in IS research". Information systems research, vol. 6, no. 4, pp. 376-394, 1995. DOI http://dx.doi.org/ $10.1287 /$ isre.6.4.376

[26] O. K. Ngwenyama and A. S. Lee. "Communication richness in electronic mail: Critical social theory and the contextuality of meaning". MIS quarterly, pp. 145-167, 1997. 
[27] W. Chen and R. Hirschheim. "A paradigmatic and methodological examination of information systems research from 1991 to 2001". Information systems journal, vol. 14, no. 3, pp. 197-235, 2004. DOI http: //dx.doi.org/10.1111/j.13652575.2004.00173.x

[28] G. Nadler. "An investigation of design methodology". Management science, vol. 13, no. 10, pp. B642, 1967. DOI http://dx.doi.org/10.1287/mnsc 13.10.B642

[29] H. A. Simon. The sciences of the artificial, vol. 136. MIT Press, 1996

[30] I. Benbasat and R. W. Zmud. "Empirical research in information systems: The practice of relevance". MIS quarterly, vol. 23, no. 1, pp. 3-16, 1999. DOI http: //dx.doi.org/10.2307/249403

[31] A. S. Lee and R. L. Baskerville. "Generalizing generalizability in information systems research". Information systems research, vol. 14, no. 3, pp. 221-243, 2003. DOI http://dx.doi.org/10.1287/isre.14.3. 221.16560 .

[32] J. Iivari, R. Hirschheim and H. K. Klein. "Towards a distinctive body of knowledge for Information Systems experts: Coding ISD process knowledge in two IS journals". Information systems journal, vol. 14, no. 4, pp. 313-342, 2004.

[33] J. F. Nunamaker Jr, M. Chen and T. D. Purdin. "Systems development in information systems research". Journal of management information systems, vol. 7, no. 3, pp. 89-106, 1990-91.

[34] H. Hasan. "Information systems development as a research method". Australian journal of information systems, vol. 11, no. 1, pp. 4-13, 2003.

[35] J. G. Walls, G. R. Widmeyer and O. A. El Sawy. "Building an information system design theory for vigilant EIS". Information systems research, vol. 3, no. 1, pp. 36-59, 1992. DOI http://dx.doi.org/10.1287/ isre.3.1.36

[36] J. M. Carroll and P. A. Swatman. "Structured-case: A methodological framework for building theory in information systems research". European Journal of Information Systems, vol. 9, no. 4, pp. 235-242, 2000. DOI http://dx.doi.org/10.1057/palgrave. ejis.3000374

[37] A. R. Hevner, S. T. March, J. Park and S. Ram. "Design science in information systems research". MIS quarterly, vol. 28, no. 1, pp. 75-105, 2004.

[38] V. Vaishnavi and W. Kuechler. "Design research in information systems", 2004. URL http://desrist org/design-research-in-information-systems/

[39] S. Gregor and D. Jones. "The anatomy of a design theory". Journal of the Association for Information Systems, vol. 8, no. 5, pp. 312-335, 2007.

[40] A. R. Hevner. "A three cycle view of design science research". Scandinavian journal of information systems, vol. 19, no. 2, p. 4, 2007.

[41] K. Peffers, T. Tuunanen, M. A. Rothenberger and S. Chatterjee. "A design science research methodology for information systems research". Journal of management information systems, vol. 24, no. 3, pp. 45-77, 2007. DOI http://dx.doi.org/10.2753/ MIS07421222240302.
[42] J. Pries-Heje and R. Baskerville. "The design theory nexus". MIS quarterly, pp. 731-755, 2008.

[43] J. Iivari and J. Venable. "Action research and design science research-Seemingly similar but decisively dissimilar". In 17th European conference on information systems, pp. 1-13. 2009.

[44] I. Junglas, B. Niehaves, S. Spiekermann, B. C. Stahl, T. Weitzel, R. Winter and R. Baskerville. "The inflation of academic intellectual capital: The case for design science research in Europe". European journal of information systems, vol. 20, no. 1, p. 1, 2011.

[45] R. Baskerville, K. Lyytinen, V. Sambamurthy and D. Straub. "A response to the design-oriented information systems research memorandum". European journal of information systems, vol. 20, no. 1, pp. 11-15, 2011. DOI http://dx.doi.org/10.1057/ejis.2010. 56

[46] S. Gregor and A. R. Hevner. "Positioning and presenting design science research for maximum impact". MIS quarterly, vol. 37, no. 2, pp. 337-356, 2013.

[47] I. Ajzen. "The theory of planned behavior". Organizational behavior and human decision processes, vol. 50, no. 2, pp. 179-211, 1991. DOI http://dx.doi.org/ 10.1016/07495978(91)90020T.

[48] F. D. Davis. "Perceived usefulness, perceived ease of use, and user acceptance of information technology". MIS quarterly, pp. 319-340, 1989. DOI http://dx. doi.org/10.2307/249008

[49] I. Marková, P. Linell, M. Grossen and A. Salazar Orvig. Dialogue in focus groups: Exploring socially shared knowledge. Equinox publishing, 2007.

[50] B. Orfali. "Active minorities and social representations: Two theories, one epistemology". Journal for the theory of social behaviour, vol. 32, no. 4, pp. 395-416, 2002. DOI http://dx.doi.org/10.1111/ 14685914.00195

[51] S. Moscovici. La psychanalyse: Son image et son public. U France Press, 1976.

[52] C. Voelklein and C. Howarth. "A review of controversies about social representations theory: A British debate". Culture 85 psychology, vol. 11, no. 4, pp. 431-454, 2005. DOI http://dx.doi.org/10.1177/ $1354067 \times 05058586$

[53] S. Moscovici. "Notes towards a description of social representations". European journal of social psychology, vol. 18, no. 3, pp. 211-250, 1988. DOI http: //dx.doi.org/10.1002/ejsp.2420180303.

[54] S. Moscovici. "Why a theory of social representations". Representations of the social, pp. 8-35, 2001.

[55] W. Wagner, G. Duveen, R. Farr, S. Jovchelovitch, F. Lorenzi-Cioldi, I. Markova and D. Rose. "Theory and method of social representations". Asian journal of social psychology, vol. 2, no. 1, pp. 95-125, 1999. DOI http://dx.doi.org/10.1111/1467839x.00028.

[56] C. Guimelli. "Locating the central core of social representations: Towards a method". European journal of social psychology, vol. 23, no. 5, pp. 555559, 1993. DOI http://dx.doi.org/10.1002/ejsp 2420230511

[57] S. Moscovici and I. Marková. "Presenting social representations: A conversation". Culture 83 psychology, vol. 4, no. 3, pp. 371-410, 1998. DOI http: //dx.doi.org/10.1177/1354067X9800400305. 
[58] G. Duveen and B. Lloyd. Social representations and the development of knowledge. Cambridge University Press, 1990. DOI http://dx.doi.org/10.1017/ CB09780511659874

[59] J. Smithson. "Using and analysing focus groups: Limitations and possibilities". International journal of social research methodology, vol. 3, no. 2, pp. 103-119, 2000. DOI http://dx.doi.org/10.1080/ 136455700405172

[60] J. Fereday and E. Muir-Cochrane. "Demonstrating rigor using thematic analysis: A hybrid approach of inductive and deductive coding and theme development". International journal of qualitative methods, vol. 5, no. 1, pp. 80-92, 2008.

[61] B. F. Crabtree and W. L. Miller. Doing qualitative research, vol. 3. Sage, 1999.

[62] K. Gleeson. "Polytextual thematic analysis for visual data". In Visual methods in psychology: Using and interpreting images in qualitative research, p. 314 . Routledge, 2012.

[63] B. Kuechler and V. Vaishnavi. "Promoting relevance in IS research: An informing system for design science research". Informing science: The international journal of an emerging transdiscipline, vol. 14, no. 1, pp. 125-138, 2011.

[64] P. Checkland. "Soft systems methodology: A thirty year retrospective". Systems research and behavioral science, vol. 17, pp. S11-S58, 2000.

[65] W. J. Orlikowski and C. S. Iacono. "Research commentary: Desperately seeking the 'IT' in IT research-A call to theorizing the IT artifact". Information systems research, vol. 12, no. 2, pp. 121-134, 2001. DOI http: //dx.doi.org/10.1287/isre.12.2.121.9700 